\title{
PERCEPTION OF WELL-BEING AMONG PATIENTS IN COMMUNITY-BASED HOME HOSPITALIZATION IN THE ISRAELI PUBLIC HEALTH SYSTEM
}

https://doi.org/10.47743/jopafl-2021-20-14

\author{
Iris MEGIDO \\ Faculty of Economics and Business Administration, “Alexandru Ioan Cuza” University, \\ Iasi, Romania \\ irismegido@gmail.com
}

\begin{abstract}
The correlation between patients' personal perceptions of their health and well-being, and the potential for recovery has gained importunate for evaluating services provided by health organizations. Community-based home hospitalization $(\mathrm{CBHH})$ is a new approach to hospitalization in the Israeli health system. We conducted a cross-sectional survey to examine the perceived well-being among $91 \mathrm{CBHH}$ patients (mean age 65.2 years, 54.9\% women) in Israel. Most participants (76.9\%) were married and 72.5\% were hospitalized due to an infectious disease. Perceived health and general well-being of the participants declined with increasing age. Married participants reporting better perceived mental and physical health. In addition, participants living in the central districts of Israel reported significantly better perceived physical and mental health compared to those living in peripheral districts. Multivariate regression analysis supported the hypotheses that married and younger patients enjoy better perceived physical well-being. At the same time, younger patients and those hospitalized with infectious diseases also perceive their mental well-being as better compared to older patients and those hospitalized in $\mathrm{CBHH}$ for other reasons. The study's findings offer useful insights for the planning and delivery of appropriate CBHH services. Particular attention should be paid to older patients, living on their own in peripheral areas of the country.

Keywords: home-based hospitalization, well-being, health system, management, patients
\end{abstract}

\section{Introduction}

The dramatic increase in the number of elderly people in the world has a significant impact on the national policy of each country and implications for the allocation of national resources and budgets. The increasing life expectancy also affects family members, relatives, and friends who assist the elderly in old age. The aging of the population and the increasing consumption of health services due to increased morbidity in old age, together with the constant rise in the number of young chronic patients, have increased health services consumption and the demand for hospital beds. Hospitalization is costly for health systems and is a health risk for many patients due to medical complications related to the hospital stay (e.g., falls, infections, mistaken medications, and unnecessary tests) and the potential functional and cognitive and functional harm to patients, especially older patients. At the same time, it is a common view in many Western countries that elderly people should age in their natural place, while using family members as the primary source of support (Iecovich, 2011). Consequently, healthcare systems in various countries have been examining alternatives to traditional inpatient care for an extensive variety of medical conditions to improve patients' care experience and the health of the population, while reducing the per capita cost of healthcare (Adams, 2019). The development of home-based 
hospitalization is of interest to physicians and nurses as well as managers of organizations that provide medical services and insurance because it has the potential for reducing financial expenditures while maintaining the provision of proper medical services (Iecovich, 2011).

In late 2017, Maccabi Health Services (MHS) was the first health maintenance organization (HMO) in Israel to implement an acute community-based home hospitalization (CBHH) program as an alternative to inpatient care (Prodan et al., 2021). Its operating model is based on existing models in other countries (Caplan et al., 2012; Lewis et al., 2012; Mendoza et al., 2009; Ram et al., 2004; Shepperd et al., 2008), with adaptation to the Israeli public health system. The target population of this hospitalization model includes patients with infectious diseases, (e.g. urinary tract infections, skin and skeletal infections, pneumonia), patients with chronic diseases that require hospitalisation due to exacerbations of the disease, and patients with metabolic disorders (e.g., dehydration). Patients considered suitable for $\mathrm{CBHH}$ are identified by a MHS nurse in the emergency department or in other hospital departments or in the community and are referred to $\mathrm{CBHH}$ as an alternative to hospital admission. The first visit by a physician or nurse is conducted within 2 to 4 hours of the patient's admission to $\mathrm{CBHH}$, followed by daily visits by a physician, nurse and additional healthcare professionals as required (e.g. social worker, physiotherapist) according to the treatment plan. Treatment within this model also includes drawing blood for laboratory tests, complete supply of all required equipment and drug treatment in all routes of administration according to the prescribed doses, hydration, regular catheterisation, or drainage treatment, wound treatment, control of pain and associated symptoms and imaging tests. The duration of $\mathrm{CBHH}$ is limited to 35 days, but the stay may be extended according to the patient's medical condition. The patients are discharged from $\mathrm{CBHH}$ according to their medical condition and the attainment of treatment goals. Patients whose health had worsened during their $\mathrm{CBHH}$ are referred to the hospital from which they had been discharged and admitted to the ward in an orderly process that is defined by the hospital's management. A telephone answering service for medical advice is available around the clock. The entire inpatient healthcare regimen is documented as soon as the treatment is over and is typed into a dedicated computer system that interfaces with MHS systems. The medical record enables communication between the staff and forms part of the patient's medical record at the HMO.

We have previously shown that $\mathrm{CBHH}$ is perceived by managers in the Israeli public health system as a good alternative to inpatient care and as a service that must be further developed, especially due to the growing shortage of beds, hospitalization complications, the patient's desire to stay at home and the increasing public health costs. Nevertheless, the participants were not unanimous with regards to the economic viability of the existing model in terms of the Israeli HMOs operating $\mathrm{CBHH}$, and the suitability of the service for all potential patients (Megido \& Prodan, 2020). The quality of medical service, patient satisfaction, and developing a generalised approach to improving the quality and safety of care, are major elements of public health systems (Garcia-Lacalle \& Bachiller, 2011). The correlation between patients' personal perceptions of their health and well-being, and the potential for recovery has become a major issue in examining the services provided by health organizations. Accordingly, obtaining a direct and subjective opinion of patients with different personal characteristics, regarding their health, in 
addition to examining objective health outcomes, is perceived as important for the overall evaluation of any health service. Since $\mathrm{CBHH}$ is a new service in Israel, we aimed to examine the perceived well-being among $\mathrm{CBHH}$ patients in Israel. We hypothesized that (1) patients' demographic characteristics (age, marital status and residential district) will influence their perception of their general well-being in $\mathrm{CBHH}$; (2) there will be differences in perceive well-being between participants hospitalized in $\mathrm{CBHH}$ due to infectious diagnoses and those hospitalized for other diagnoses.

\section{Research methodology}

\section{Study design}

This study was a cross-sectional survey study that was part of a larger mixed methods study (Megido \& Prodan, 2020). The study was approved by MHS's ethics committee (approval number 004-20-MHS, date 11 March 2020).

\section{Study participants and setting}

Participants were recruited to the study using convenience sampling. Hence, no criteria for inclusion were identified before the participants were selected. The size of the planned sample included all patients discharged from $\mathrm{CBHH}$ of $\mathrm{MHS}$ from July to September 2020. Study participants were patients who had received treatment in a CBHH setting at Maccabi Health Services (HM'O) between July and September 2020. Hebrewspeaking patients (or ones with a Hebrew-speaking caregiver) who had been treated in a $\mathrm{CBHH}$ setting for at least 3 days during the two months that preceded the study and who gave their consent to participate in the study were included. At the time of the study approximately 50 patients were hospitalized in $\mathrm{CBHH}$ every month. The sample selected for this study constitutes approximately $70 \%$ of these patients, encompassing all patients or caregivers who have expressed their consent to complete the questionnaire. The study assumes that the sample selected for this study represents the entire population of CBHH patients in Israel at the time of the study.

\section{Research tool and data collection}

The research tool used for data collection in this study was the Patient-Reported Outcomes Measurement Information System 10 (PROMIS-10) Global Health survey is a ten-item questionnaire that was developed by the United States National Institute of Health to assess generic health-related quality of life compared with normal values for the general population (Hays et al., 2009). It measures five domains: physical function, fatigue, pain, emotional distress, and social health on a five-point response matrix. Study participants (or their caregiver) completed the questionnaire. Completed questionnaires were collected and the data was typed into an Excel sheet (Microsoft Office 2019 software).

\section{Data analysis}

The data were analyzed using IBM SPSS Statistics for Windows, Version 25.0. (Armonk, NY: IBM Corp). Descriptive statistics of subject data was performed and expressed as means and standard deviations (SD) for continuous variables and as number and percentage for categorical variables. The two-sample T-test for independent samples was applied for testing the statistical significance of the difference in physical health and 
mental health by age, marital status, participant residential district and reason for being admitted to $\mathrm{CBHH}$. Multivariate linear regression models were applied to test the statistical significance of the difference in physical and mental health by demographic and clinical variables. All statistical tests were two-sided. P-values less than 0.05 were considered statistically significant.

\section{Results}

A total of 91 participants (mean age [SD], 65.2 years [16.9]; 54.9\% women) were included in the study. The Participants' sociodemographic characteristics and reason for CBHH are shown in table 1 . Most participants (76.9\%) were married. The main reason for hospitalization was an infectious disease (72.5\% of participants).

Table 1. Participant characteristics

\begin{tabular}{|c|c|}
\hline Variable & Study population N=91 \\
\hline Sex, n (\%) & $41(45.1 \%)$ \\
\hline Men & $50(54.9 \%)$ \\
\hline Women & $65.2(16.9)$ \\
\hline Age, years, mean (SD) & $6(6.6 \%)$ \\
\hline Family status & $70(76.9 \%)$ \\
\hline Single & $15(16.5 \%)$ \\
\hline Married & $31(34.1 \%)$ \\
\hline Divorced/widowed & $18(19.8 \%)$ \\
\hline District & $29(31.9 \%)$ \\
\hline Jerusalem & $13(14.3 \%)$ \\
\hline Central & $66(72.5 \%)$ \\
\hline Northern & $25(27.5 \%)$ \\
\hline Southern & \\
\hline Main reason for CBHH & $43(47.3 \%)$ \\
\hline Infectious disease & $48(52.7 \%)$ \\
\hline Other & \\
\hline Questionnaire completed by & \\
\hline Patient & SD standard deviation \\
\hline Caregiver & \\
\hline CBHH = commity-based home hospitalization, SD & \\
\hline
\end{tabular}

Table 2 presents the means of the PROMIS questionnaire domains. The mean of physical health for all patients was 39.1 (SD, 11.4) and the mean of mental health was 45.2 (SD, 12.6).

Table 2. Summary of PROMIS questionnaire results

\begin{tabular}{|c|c|c|c|c|}
\hline & \multicolumn{5}{|c|}{ Study population N=91 } \\
\hline PROMIS domain & Mean & SD & Actual range & Possible range \\
\hline Physical health & 39.1 & 11.4 & $19.9-67.7$ & $16.2-67.7$ \\
\hline Mental health & 45.2 & 12.6 & $21.2-67.6$ & $1-5$ \\
\hline Q6 (global 9r) & 2.6 & 1.6 & $1-5$ & \\
\hline \multicolumn{7}{|c|}{ SD=standard deviation } \\
\hline
\end{tabular}

Analysis of the physical and mental health domains of the PROMIS questionnaire by participants' age (Table 3) showed that both mean physical and mental health were 
statistically significantly higher in participants younger than 55 years compared to those 55 years of age or older ( $<0.0001$ for both). Hence, younger patients in CBHH perceive their well-being as better than older patients.

Table 3. Comparison of the perceived physical and mental health of the study participants by age

\begin{tabular}{|c|c|c|c|c|c|c|}
\hline \multirow[t]{2}{*}{ PROMIS domain } & \multicolumn{2}{|c|}{$<55$ years $\mathrm{N}=19$} & \multicolumn{3}{|c|}{$\geq 55$ years $\mathrm{N}=72$} & \\
\hline & mean & (SD) & mean & (SD) & $\mathrm{t}(89)$ & $\mathrm{P}$ value \\
\hline Physical health & 46.4 & $(12.4)$ & 37.2 & $(10.3)$ & 3.32 & $<0.001$ \\
\hline Mental health & 54.1 & (12.6) & 42.9 & (11.6) & 3.67 & $<0.001$ \\
\hline
\end{tabular}

Analysis of the physical and mental health domains of the PROMIS questionnaire by participants' marital status (Table 4) showed that mean perceived physical health was statistically significantly higher in married participants compared to participants who were single, divorced or widowed $(\mathrm{p}<0.05)$ while the difference in mean perceived mental health between married participants and those who were single, divorced or widowed only showed a trend for statistical significance $(\mathrm{p}=0.076)$.

Table 4. Comparison of the perceived physical and mental health of the study participants by marital status

\begin{tabular}{|c|c|c|c|c|c|c|}
\hline \multirow{2}{*}{ PROMIS domain } & \multicolumn{2}{|c|}{ Married $\mathrm{N}=70$} & \multicolumn{3}{|c|}{ Single/divorced/widowed N=21 } & \multirow[b]{2}{*}{$\mathrm{P}$ value } \\
\hline & mean & $(\mathrm{SD})$ & mean & $(\mathrm{SD})$ & $\mathrm{t}(89)$ & \\
\hline Physical health & 40.6 & $(11.5)$ & 34.0 & (9.3) & -2.41 & $<0.05$ \\
\hline Mental health & 46.5 & $(12.7)$ & 40.9 & $(11.8)$ & -1.79 & 0.076 \\
\hline
\end{tabular}

Analysis of the physical and mental health domains of the PROMIS questionnaire by participants' residential district (Table 5) showed that mean perceived physical and mental health were statistically significantly higher in participants living in the central districts of Israel compared to those living in peripheral districts $(\mathrm{p}<0.022$ for both)

Table 5. Comparison of the perceived physical and mental health of the study participants by residential district

\begin{tabular}{|c|c|c|c|c|c|c|}
\hline \multirow{2}{*}{ PROMIS domain } & \multicolumn{2}{|c|}{ Central* N=49 } & \multicolumn{2}{|c|}{ Peripheral** N=42 } & P value \\
\cline { 2 - 7 } & mean & (SD) & mean & $(\mathrm{SD})$ & $\mathrm{t}(89)$ & 0.022 \\
\hline Physical health & 41.6 & 12.5 & 36.2 & 9.2 & $-2.34 *$ & 0.022 \\
\hline Mental health & 48.0 & 13.3 & 41.9 & 11.1 & $-2.34 *$ & $*$ \\
\hline \multicolumn{6}{r}{ SD=standard deviation. P value by two-sample T-test for independent samples } \\
*Jerusalem and Central districts; **Northern and Southern districts
\end{tabular}

Analysis of the physical and mental health domains of the PROMIS questionnaire by participants' hospitalization reason (Table 6) showed no difference in mean perceived physical health, but mean perceived mental health was statistically significantly higher in those hospitalized for infection compared to those hospitalized for other reasons $(p=0.046)$.

Table 6. Comparison of the perceived physical and mental health of the study participants by reason for CBHH 


\begin{tabular}{|c|c|c|c|c|c|c|}
\hline \multirow{2}{*}{ PROMIS domain } & \multicolumn{2}{|c|}{ Infection $\mathrm{N}=66$} & \multicolumn{2}{|c|}{ Other reason $\mathrm{N}=25$} & \multirow[b]{2}{*}{$\mathrm{t}(89)$} & \multirow[b]{2}{*}{ P value } \\
\hline & mean & (SD) & mean & (SD) & & \\
\hline Physical health & 39.9 & (11.6) & 36.8 & $(10.6)$ & 1.16 & 0.249 \\
\hline Mental health & 46.8 & (12.5) & 40.9 & (12.3) & 2.02 & 0.046 \\
\hline
\end{tabular}

Multiple linear regression was utilized to examine the relative contribution of sex, age, marital status, residential district and hospitalization reason on physical health (Table 7 ). The explained variability was $\mathrm{R} 2=19.2 \%, \mathrm{p}=0.002$, when age and marital status were found significant. Hence younger and married participants had better perceived physical health. The expected physical health perception of patients facing home hospitalization based on their demographic data, and the reason for hospitalization can be calculated by the following equation: $42.3+(0.62 *$ Sex $)-(0.2 *$ Age $)-(2.54 *$ hospitalization reason (infection/other reason) $+(6.22 *$ marital status (not married/married $))+(2.82 *$ residential district (not central/central).

Table 7. Multiple linear regression for physical well-being by sex, age, family status, living place and hospitalization reason

\begin{tabular}{|c|c|c|c|c|}
\hline Physical health & B & SE B & Beta & P value \\
\hline Sex & 0.62 & 2.34 & 0.027 & 0.791 \\
\hline Age & -0.20 & 0.07 & -0.293 & 0.004 \\
\hline $\begin{array}{c}\text { Hospitalization } \\
\text { reason }\end{array}$ & -2.54 & 2.59 & -0.100 & 0.331 \\
\hline Marital status & 6.22 & 2.75 & 0.232 & 0.026 \\
\hline Residence & 2.82 & 2.37 & 0.124 & 0.237 \\
\hline
\end{tabular}

Multiple linear regression was utilized to examine the relative contribution of sex, age, marital status, residential district and hospitalization reason on perceived mental health (Table 8). The explained variability was R2=28.5\%, $\mathrm{p}<0.001$, when age and hospitalization reason were found significant. Hence younger participants and those hospitalized due to infection had better perceived mental health. The expected mental health perception of patients facing home hospitalization based on their demographic data, and the reason for hospitalization can be calculated by the following equation: $58.3-(1.18 *$ Sex $)-(0.32 *$ Age $)-(5.54 *$ hospitalization reason (infection/other reason $)+(4.51 *$ marital status (not married/married $))+(2.2 *$ residential district (not central/central)

Table 8. Multiple linear regression for physical well-being by sex, age, family status, living place and hospitalization reason

\begin{tabular}{|c|c|c|c|c|}
\hline Mental health & B & SE B & Beta & P value \\
\hline Sex & -1.18 & 2.45 & -0.047 & 0.630 \\
\hline Age & -0.32 & 0.07 & -0.433 & $<0.001$ \\
\hline Hospitalization reason & -5.54 & 2.72 & -0.197 & 0.045 \\
\hline Marital status & 4.51 & 2.89 & 0.151 & 0.122 \\
\hline Residence & 2.20 & 2.48 & 0.089 & 0.377 \\
\hline
\end{tabular}




\section{Discussion}

The findings indicate that there several factors contribute to the perceived general well-being of patients in $\mathrm{CBHH}$ in Israel. The first factor is patients' age. The study's finding showed that the perceived health and general well-being of patients in $\mathrm{CBHH}$ declines with increasing age. These findings are in line with the Israeli Central Bureau of Statistics' report, which showed that $95.3 \%$ of those aged $20-44$ and $80.7 \%$ of those aged 45-65 report a very good or good state of health, whereas among those aged 65 and older, only $56.6 \%$ report a very good or good state of health (CBS, 2019). The proportion of people who assess their health condition as very good or good diminishes with age. Negative age-related attitudes have a strong influence on people in early old age, when they have yet to form a self-identity and a sense of belonging to an older age group. Therefore, addressing these age groups who are not yet defined as "elderly" but are no longer young is particularly significant, with the aim of promoting higher perceived personal well-being (Khalaila, 2013). The need to assess and promote perceived quality of life in older age is reinforced by repeated research findings that improving self-perceived health in older age might lead to improved quality of life and reduced morbidity and mortality (Cesari et al., 2008; Ford et al., 2008).

Our results also show that marital status affects patients' perception of general wellbeing in $\mathrm{CBHH}$, with married participants reporting better perceived mental and physical health. This may be explained by the fact that people living alone must see to their own basic physical needs independently, and may finds themselves lonelier and reliant on visits by friends and family, while married people have constant physical, social, and emotional support and thus experiences the crisis period of the hospitalization more positively. Studies on the association between marriage, spousal relations, and living with a spouse have showed that married people have higher subjective perceived personal well-being (Mikucka, 2016; Stutzer \& Frey, 2006). Married people who share a long-term intimate relationship, friendship, and daily contact, tend to be happier than unmarried ones and feel that the relationship provides them with emotional and social support that helps them handle stressful and crisis events that might be a threat to their well-being (Nelson-Coffey, 2018). The negative health consequences of social isolation find powerful expression, especially among those most in need of support, such as older people or isolated groups on the margins of society (Cacioppo \& Hawkley, 2003). Recognition of the health outcomes of loneliness is important in the management and development of tailored intervention programs for the prevention and reduction of negative outcomes of loneliness, such as low perception of general well-being among $\mathrm{CBHH}$ patients living alone.

Another major finding is the association between residential district and perception of general well-being in $\mathrm{CBHH}$. An explanation for this finding can be found in the differences in the level of accessibility to services in general and medical services, in particular between the center of the country and the periphery, The literature supports this finding and relates to the topic of disparities and inequality in health services between groups within the same country. When examining inequality in health systems around the world, place of residence is an important field of influence. The World Health Organization has defined inequality in health as an international problem and conducts measurement, 
monitoring, and reflection in countries in order to form standards for reducing inequality between population groups (Hosseinpoor et al., 2015). In Israel there is a national focus on inequality in access to health services, with one of the main areas being the comparison between the state of health in peripheral areas and in the center of the country. It is evident that when comparing the periphery and the center regarding health issues such as life expectancy, infant mortality, and risk factors for chronic morbidity, there are differences between those living in the center and in the periphery, indicating a lower level of health in the periphery. Another important measure examined is self-evaluation of one's health. Current surveys found that the proportion of those reporting a good state of health is higher in towns located in central Israel than in peripheral areas (CBS, 2019). The Israeli government is producing positive incentives for community health services to reduce inequality in health and expects community-based health services to initiate programs to reduce gaps between groups, with an emphasis on programs to reduce health gaps in peripheral societies. Reducing inequality in public policy is a social goal in itself and is especially important in cases where the system can reduce differences between different groups, which are perceived as unfair, through tailored management. Actions aimed at reducing and preventing inequality should be a key component of public health policy. Low perceptions of general well-being can adversely affect treatment outcomes and cause a bias in $\mathrm{CBHH}$ outcomes among patients living in different areas. Hence, it can be estimated that in the absence of adapted CBHH models for the periphery, the perception of well-being of $\mathrm{CBHH}$ patients living in the periphery will continue to be low and may adversely affect the health outcome of $\mathrm{CBHH}$.

Additional finding addresses the association between the diagnosis of patients in $\mathrm{CBHH}$ and patients' perception of their health. The research results show that research participants treated in $\mathrm{CBHH}$ due to the diagnosis of an infectious disease perceived their mental well-being as better than did patients who received the service due to other diagnoses. No conspicuous differences were found in the perception of one's physical wellbeing between the group treated in $\mathrm{CBHH}$ due to diagnosis of an infectious disease and the group treated in $\mathrm{CBHH}$ due to other diagnoses. The range of diagnoses suitable for acute home hospitalisation is very wide. Target diagnoses include, among others, urinary tract infections as well as infectious diseases that require lengthy care, such as pneumonia, osteomyelitis, endocarditis, complicated diverticulitis, and cellulitis (Casteli et al., 2020; Cotton et al., 2000; Donald et al., 2005; McCarthy et al., 2015; Mendoza et al., 2009; Otero et al., 2010; Patel et al., 2008; Simpson et al., 2019). Other medical conditions suitable for home care include patients with deterioration of chronic illnesses such as heart failure, stroke, pulmonary embolism, chronic obstructive pulmonary disease (COPD), psychiatric disease (Barker et al., 2021; Caplan et al., 2012; Casteli et al., 2020; Corral Gudino et al., 2017; Corwin et al., 2005; Davies et al., 2000; Dowell et al., 2018; Echevarria et al., 2016; Goncalves-Bradley et al., 2017; Huntley et al., 2017; Jeppesen et al., 2012; Otero et al., 2010; Qaddoura et al., 2015; Ram et al., 2004; Richards et al., 2005; Shepperd et al., 2009; Shepperd et al., 2008; Shepperd \& Iliffe, 1998; Shepperd et al., 2016; Wolter et al., 2004), . Cancer, including children with cancer and patients undergoing therapeutic treatment (Cool et al., 2018; Hansson et al., 2011; Hansson et al., 2013; Massano et al., 2020), and end-of-life patients (Shepperd et al., 2021).

Despite the extensive literature on medical conditions suitable for $\mathrm{CBHH}$, there is a lack of research literature on aspects relating to the type of diagnoses in $\mathrm{CBHH}$ and 
patients' health perception, and the effects these have on managing $\mathrm{CBHH}$. Therefore, this finding is presented as an innovation of the current study. This finding can be explained because patients with a diagnosis of infectious disease are most often healthy people who are on $\mathrm{CBHH}$ due to the current acute illness that requires treatment but has no long-term consequences for their health and is not accompanied in the long term. In contrast, patients suffering from a chronic disease, such as heart disease or chronic lung disease, suffer from symptoms of the chronic disease on a permanent basis, so it is not surprising that even when treating an acute problem, their perceived mental well-being is lower. As for the perception of physical well-being, the study included people who were ill with an acute illness at the time, when even healthy people generally felt worse.

The linear regression conducted supports the hypotheses that married and younger patients enjoy better perceived physical well-being. At the same time, younger patients and those hospitalized with infectious diseases also perceive their mental well-being as good compared to older patients and those hospitalized in $\mathrm{CBHH}$ for other reasons. Since the explained variance in the regression equations were relatively low (19\% and $28 \%$ for physical and mental health perception, respectively), there may be other significant variables that affect the sense of general well-being that were not included in this study. Other limitations of the study include its relatively small sample size, its cross-sectional design, which only allows to view the results in a specific point in time, its sampling method and self-report nature. The reason for choosing a convenience sample as an appropriate method for this study is the planned duration of the study. Nevertheless, this did not come at the expense of a representative sample in terms of the residential districts of the study participants, their age and gender. The advantages of the method are the simplicity of sampling and programming for data collection in a short time (Creswell \& Creswell, 2018; Saunders et al., 2012). The possibility exists that in cases in which care givers completed the questionnaires, they may have affected the patient's responses.

\section{Conclusions}

The findings offer useful insights for the planning and delivery of appropriate $\mathrm{CBHH}$ services. Particular attention should be paid to older patients, living on their own in peripheral areas of the country. The limitations of the study relate to the examination of additional variables that may affect the well-being of patients in $\mathrm{CBHH}$. Since in this study the variance explained in the regression equations was relatively low (19\% and $28 \%$ for perceived physical and mental health, respectively), other significant variables that were not tested in this study may affect the overall sense of well-being.

\section{References}

1. Adams, F. M. (2019). The impact on cost, quality, and patient satisfaction when delivering care to acutely ill adults in an at-home care model versus an inpatient hospital setting. Theses and Capstones, 543. https://scholars.unh.edu/honors/453

2. $\quad$ Barker, R. E., Brighton, L. J., Maddocks, M., Nolan, C. M., Patel, S., Walsh, J. A., Polgar, O., Wenneberg, J., Kon, S. S. C., Wedzicha, J. A., Man, W. D. C., \& Farquhar, M. (2021). Integrating HomeBased Exercise Training with a Hospital at Home Service for Patients Hospitalised with Acute Exacerbations 
of COPD: Developing the Model Using Accelerated Experience-Based Co-Design. Int J Chron Obstruct Pulmon Dis, 16, 1035-1049. https://doi.org/10.2147/COPD.S293048

3. Cacioppo, J. T., \& Hawkley, L. C. (2003). Social Isolation and Health, with an Emphasis on Underlying Mechanisms. Perspectives in Biology and Medicine, 46 (3), S39-S52.

4. $\quad$ Caplan, G. A., Sulaiman, N. S., Mangin, D. A., Aimonino Ricauda, N., Wilson, A. D., \& Barclay, L. (2012). A meta-analysis of "hospital in the home". Med J Aust, 197 (9), 512-519. https://doi.org/10.5694/mja12.10480

5. $\quad$ Casteli, C. P. M., Mbemba, G. I. C., Dumont, S., Dallaire, C., Juneau, L., Martin, E., Laferrière, M.C., \& Gagnon, M.-P. (2020). Indicators of home-based hospitalization model and strategies for its implementation: a systematic review of reviews. Systematic Reviews, 9 (1), 172. https://doi.org/10.1186/s13643-020-01423-5 CBS. (2019).

6. $\quad$ Cesari, M., Onder, G., Zamboni, V., Manini, T., Shorr, R. I., Russo, A., Bernabei, R., Pahor, M., \& Landi, F. (2008). Physical function and self-rated health status as predictors of mortality: results from longitudinal analysis in the ilSIRENTE study. BMC Geriatr, 8, 34. https://doi.org/10.1186/1471-2318-8-34 7. Cool, L., Vandijck, D., Debruyne, P., Desmedt, M., Lefebvre, T., Lycke, M., De Jonghe, P. J., Pottel, H., Foulon, V., \& Van Eygen, K. (2018). Organization, quality and cost of oncological home-hospitalization: A systematic review. Crit Rev Oncol Hematol, 126, 145-153. https://doi.org/10.1016/j.critrevonc.2018.03.011

8. $\quad$ Corral Gudino, L., Borao Cengotita-Bengoa, M., Jorge Sanchez, R. J., \& Garcia Aparicio, J. (2017). [The patient and the crossing between Primary and Hospital care. Systematic review of trials for the implementation of tools for integration in Spain]. An Sist Sanit Navar, 40 (3), 443-459. https://doi.org/10.23938/ASSN.0119

9. $\quad$ Corwin, P., Toop, L., McGeoch, G., Than, M., Wynn-Thomas, S., Wells, J. E., Dawson, R., Abernethy, P., Pithie, A., Chambers, S., Fletcher, L., \& Richards, D. (2005). Randomised controlled trial of intravenous antibiotic treatment for cellulitis at home compared with hospital. BMJ, 330 (7483), 129. https://doi.org/10.1136/bmj.38309.447975.EB

10. Cotton, M. M., Bucknall, C. E., Dagg, K. D., Johnson, M. K., MacGregor, G., Stewart, C., \& Stevenson, R. D. (2000). Early discharge for patients with exacerbations of chronic obstructive pulmonary disease: a randomized controlled trial. Thorax, 55 (11), 902-906. https://doi.org/10.1136/thorax.55.11.902

11. Creswell, J. W., \& Creswell, J. D. (2018). Research design: qualitative, quantitative, and mixed methods approaches. Fifth edition. SAGE.

12. Davies, L., Wilkinson, M., Bonner, S., Calverley, P. M., \& Angus, R. M. (2000). "Hospital at home" versus hospital care in patients with exacerbations of chronic obstructive pulmonary disease: prospective randomised controlled trial. BMJ, 321 (7271), 1265-1268. https://doi.org/10.1136/bmj.321.7271.1265

13. Donald, M., Marlow, N., Swinburn, E., \& Wu, M. (2005). Emergency department management of home intravenous antibiotic therapy for cellulitis. Emerg Med J, 22 (10), 715-717. https://doi.org/10.1136/emj.2004.018143

14. Dowell, S., Moss, G., \& Odedra, K. (2018). Rapid response: a multiprofessional approach to hospital at home. Br J Nurs, 27 (1), 24-30. https://doi.org/10.12968/bjon.2018.27.1.24

15. Echevarria, C., Brewin, K., Horobin, H., Bryant, A., Corbett, S., Steer, J., \& Bourke, S. C. (2016). Early Supported Discharge/Hospital At Home For Acute Exacerbation of Chronic Obstructive Pulmonary Disease: A Review and Meta-Analysis. COPD, 523-533. https://doi.org/10.3109/15412555.2015.1067885

16. Ford, J., Spallek, M., \& Dobson, A. (2008). Self-rated health and a healthy lifestyle are the most important predictors of survival in elderly women. Age Ageing, 37 (2), 194-200. https://doi.org/10.1093/ageing/afm171

17. Garcia-Lacalle, J., \& Bachiller, P. (2011). Dissecting hospital quality. Antecedents of clinical and perceived quality in hospitals. Int $J$ Health Plann Manage, 26 (3), 264-281. https://doi.org/10.1002/hpm.1076

18. Goncalves-Bradley, D. C., Iliffe, S., Doll, H. A., Broad, J., Gladman, J., Langhorne, P., Richards, S. H., \& Shepperd, S. (2017). Early discharge hospital at home. Cochrane Database Syst Rev, 6, CD000356. https://doi.org/10.1002/14651858.CD000356.pub4

19. Hansson, H., Hallstrom, I., Kjaergaard, H., Johansen, C., \& Schmiegelow, K. (2011). Hospitalbased home care for children with cancer. Pediatr Blood Cancer, 57 (3), 369-377. https://doi.org/10.1002/pbc.23047 
20. Hansson, H., Kjaergaard, H., Johansen, C., Hallstrom, I., Christensen, J., Madsen, M., \& Schmiegelow, K. (2013). Hospital-based home care for children with cancer: feasibility and psychosocial impact on children and their families. Pediatr Blood Cancer, 60 (5), 865-872. https://doi.org/10.1002/pbc.24474

21. Hays, R. D., Bjorner, J. B., Revicki, D. A., Spritzer, K. L., \& Cella, D. (2009). Development of physical and mental health summary scores from the patient-reported outcomes measurement information system (PROMIS) global items. Qual Life Res, 18 (7), 873-880. https://doi.org/10.1007/s11136-009-94969

22. Hosseinpoor, A. R., Bergen, N., \& Magar, V. (2015). Monitoring inequality: an emerging priority for health post-2015. Bull World Health Organ, 93 (9), 591-591A. https://doi.org/10.2471/BLT.15.162081

23. Huntley, A. L., Chalder, M., Shaw, A. R. G., Hollingworth, W., Metcalfe, C., Benger, J. R., \& Purdy, S. (2017). A systematic review to identify and assess the effectiveness of alternatives for people over the age of 65 who are at risk of potentially avoidable hospital admission. BMJ Open, 7 (7), e016236. https://doi.org/10.1136/bmjopen-2017-016236

24. Iecovich, E. (2011). Home Care for Frail Older Adults: Issues, Services and Programs. Eshel.

25. Jeppesen, E., Brurberg, K. G., Vist, G. E., Wedzicha, J. A., Wright, J. J., Greenstone, M., \& Walters, J. A. (2012). Hospital at home for acute exacerbations of chronic obstructive pulmonary disease. Cochrane Database Syst Rev, (5), CD003573. https://doi.org/10.1002/14651858.CD003573.pub2

26. Khalaila, R. (2013). Patients' family satisfaction with needs met at the medical intensive care unit. Journal of Advanced Nursing, 69 (5), 1172-1182. https://doi.org/https://doi.org/10.1111/j.13652648.2012.06109.x

27. Lewis, G., Wright, L., \& Vaithianathan, R. (2012). Multidisciplinary case management for patients at high risk of hospitalization: comparison of virtual ward models in the United kingdom, United States, and Canada. Popul Health Manag, 15 (5), 315-321. https://doi.org/10.1089/pop.2011.0086

28. Massano, D., Cosma, L., Garolla, M., Sainati, L., \& Biffi, A. (2020). Hospital-based home care for children with cancer during the COVID-19 pandemic in northeastern Italy. Pediatr Blood Cancer, 67 (12), e28501. https://doi.org/10.1002/pbc.28501

29. McCarthy, D., Ryan, J., \& Klein, S. (2015). Models of Care for High-Need, High-Cost Patients: An Evidence Synthesis. Issue Brief (Commonw Fund), 31, 19. https://www.ncbi.nlm.nih.gov/pubmed/26591906

30. Megido, I., \& Prodan, A. (2020). Community-based home hospitalization in the Israeli public health system: A qualitative study of the views of health system managers. Journal of Public Administration, Finance and Law, 18 (67-77).

31. Mendoza, H., Martin, M. J., Garcia, A., Aros, F., Aizpuru, F., Regalado De Los Cobos, J., Bello, M. C., Lopetegui, P., \& Cia, J. M. (2009). 'Hospital at home' care model as an effective alternative in the management of decompensated chronic heart failure. Eur J Heart Fail, 11 (12), 1208-1213. https://oi.org/10.1093/eurjhf/hfp143

32. Mikucka, M. (2016). The life satisfaction advantage of being married and gender specialization. Journal of Marriage and Family, 78, 759-779.

33. Nelson-Coffey, S. (2018). Married . . . with children: The science of well-being in marriage and family life. . In E. Diener, S. Oishi, \& L. Tay (Eds.), Handbook of well-being. DEF Publishers.

34. Otero, R., Uresandi, F., Jimenez, D., Cabezudo, M. A., Oribe, M., Nauffal, D., Conget, F., Rodriguez, C., \& Cayuela, A. (2010). Home treatment in pulmonary embolism. Thromb Res, 126 (1), e1-5. https://doi.org/10.1016/j.thromres.2009.09.026

35. Patel, H., Shafazand, M., Ekman, I., Hojgard, S., Swedberg, K., \& Schaufelberger, M. (2008). Home care as an option in worsening chronic heart failure -- a pilot study to evaluate feasibility, quality adjusted life years and cost-effectiveness. Eur J Heart Fail, $10 \quad$ (7), 675-681. https://doi.org/10.1016/j.ejheart.2008.05.012

36. Prodan, A., Megido, I., \& Soudri, A. (2021). Management of Community-Based Home Hospitalization (CBHH) in Israeli Public Health System. International Journal of Comparative Management, 20, 2019. https://doi.org/10.24818/RMCI.2019.5.544

37. Qaddoura, A., Yazdan-Ashoori, P., Kabali, C., Thabane, L., Haynes, R. B., Connolly, S. J., \& Van Spall, H. G. (2015). Efficacy of Hospital at Home in Patients with Heart Failure: A Systematic Review and Meta-Analysis. PLoS One, 10 (6), e0129282. https://doi.org/10.1371/journal.pone.0129282 
38. Ram, F. S., Wedzicha, J. A., Wright, J., \& Greenstone, M. (2004). Hospital at home for patients with acute exacerbations of chronic obstructive pulmonary disease: systematic review of evidence. BMJ, 329 (7461), 315. https://doi.org/10.1136/bmj.38159.650347.55

39. Richards, D. A., Toop, L. J., Epton, M. J., McGeoch, G. R., Town, G. I., Wynn-Thomas, S. M., Dawson, R. D., Hlavac, M. C., Werno, A. M., \& Abernethy, P. D. (2005). Home management of mild to moderately severe community-acquired pneumonia: a randomised controlled trial. Med J Aust, 183 (5), 235238. https://www.ncbi.nlm.nih.gov/pubmed/16138795

40. Saunders, M., Lewis, P., \& Thornhill, A. (2012). Research Methods for Business Students. 6th edition Pearson Education Limited

41. Shepperd, S., Doll, H., Angus, R. M., Clarke, M. J., Iliffe, S., Kalra, L., Ricauda, N. A., Tibaldi, V., \& Wilson, A. D. (2009). Avoiding hospital admission through provision of hospital care at home: a systematic review and meta-analysis of individual patient data. CMAJ, 180 (2), 175-182. https://doi.org/10.1503/cmaj.081491

42. Shepperd, S., Doll, H., Angus, R. M., Clarke, M. J., Iliffe, S., Kalra, L., Ricauda, N. A., \& Wilson, A. D. (2008). Admission avoidance hospital at home. Cochrane Database Syst Rev, (4), CD007491. https://doi.org/10.1002/14651858.CD007491

43. Shepperd, S., Goncalves-Bradley, D. C., Straus, S. E., \& Wee, B. (2021). Hospital at home: homebased end-of-life care. Cochrane Database Syst Rev, 3, CD009231. https://doi.org/10.1002/14651858.CD009231.pub3

44. Shepperd, S., \& Iliffe, S. (1998). The effectiveness of hospital at home compared with in-patient hospital care: a systematic review. J Public Health Med, 20 (3), 344-350. https://doi.org/10.1093/oxfordjournals.pubmed.a024778

45. Shepperd, S., Iliffe, S., Doll, H. A., Clarke, M. J., Kalra, L., Wilson, A. D., \& Goncalves-Bradley, D. C. (2016). Admission avoidance hospital at home. Cochrane Database Syst Rev, 9, CD007491. https://doi.org/10.1002/14651858.CD007491.pub2

46. $\quad$ Simpson, M., Macias Tejada, J., Driscoll, A., Singh, M., Klein, M., \& Malone, M. (2019). The Bundled Hospital Elder Life Program-HELP and HELP in Home Care-and Its Association With Clinical Outcomes Among Older Adults Discharged to Home Healthcare. J Am Geriatr Soc, 67 (8), 1730-1736. https://doi.org/10.1111/jgs.15979

47. Stutzer, A., \& Frey, B. S. (2006). Does marriage make people happy, or do happy people get married? Journal of Socio-Economics, 35, 326-347.

48. Wolter, J. M., Cagney, R. A., \& McCormack, J. G. (2004). A randomized trial of home vs hospital intravenous antibiotic therapy in adults with infectious diseases. $J$ Infect, 48 (3), 263-268. https://doi.org/10.1016/S0163-4453(03)00135-X 